\title{
Modelling of Heat Pumps with Calibrated Parameters Based on Manufacturer Data
}

\author{
Massimo Cimmino $^{1}$ Michael Wetter $^{2}$ \\ ${ }^{1}$ Department of Mechanical Engineering, Polytechnique Montreal, Montreal QC, Canada, \\ massimo.cimminolpolymtl.ca \\ ${ }^{2}$ Lawrence Berkeley National Laboratory, Energy Technologies Area, Building Technology and Urban Systems Division, \\ Simulation Research Group, Berkeley CA, USA, mwetter@lbl.gov
}

\begin{abstract}
A Modelica model for the simulation of heat pumps is presented. The model uses a simplified vapor compression cycle with only five refrigerant states. Parameters to the model are evaluated using an optimization procedure to minimize the differences between the model predicted heating capacities and power input and those provided in the manufacturer technical data. The optimization process is done from a Python implementation of the heat pump model.

The model is first tested by verifying that calibration from performance data generated by the heat pump model results in the same parameters as the ones used in the generation of the performance data. In the presented example, calibrated parameters were found close to the original parameters used to generate the data, except for the evaporator heat transfer coefficient for which the model was found not to be very sensitive. In a second example, the model is calibrated against manufacturer data. The heating capacities and power input calculated from the calibrated model are within $2.7 \%$ and $4.7 \%$ of the manufacturer data, respectively. Finally, the computational performance of the model is tested in a system simulation of a hydronic heating system. The simulation using the presented heat pump model was executed in 48 seconds, compared to 17 seconds for the same system using a simple boiler model.
\end{abstract}

Keywords: $\quad$ Heat Pump, Vapor Compression Cycle, Model Calibration

\section{Introduction}

Heat pump systems offer great potential for the reduction of energy use for heating, cooling and heat recovery, and are attractive heat delivery systems in applications involving low temperature thermal networks (Lund et al., 2014). To optimize the design and evaluate the energy performance of such systems, efficient simulation tools are required to model the annual behavior of the system components.

Heat pump models can be divided into two major categories: empirical models and refrigerant cycle models. Empirical models are obtained by mapping the heat pump performance in terms of capacity, power input and coefficient of performance to the operating conditions, i.e. the water mass flow rates and temperatures on the load and source side of the heat pump. The performance map can then be interpolated during numerical simulations, or used to produce an equation-fit of the heat pump performance. On the other hand, refrigerant cycle models are obtained from first principles, with varying degree of details in the definition of each heat pump component.

Empirical models have been shown to provide good approximations of the heat pump performance as shown, for instance, by Swider (2003), Lee and Lu (2010) and Carbonnell et al. (2012). However, researchers have pointed out that these models might not be suitable for extrapolation of the heat pump performance outside of the operating conditions used to formulate the model (Jin, 2002; Scarpa et al., 2012). Unfortunately, such extrapolation is often required as manufacturers generally provide performance data for a narrow operating range. Models based on first principles offer better potential to accurately predict the heat pump performance over a wider range of operating conditions.

Refrigerant cycle models are often more demanding in terms of computational time when compared to empirical models, and may require parameters not provided by manufacturers. Simplified vapor compression cycles may be used to reduce the computational time (Domanski and McLinden, 1992; Jin, 2002; Lemort and Bertagnolio, 2010; Scarpa et al., 2012). These simplified cycles divide the vapor compression cycle into a limited number of steps and refrigerant states, thereby reducing the number of usually computationally expensive - refrigerant thermodynamic properties to evaluate. Parameters to these models may then be obtained through calibration, using an optimization procedure to minimize the model predicted heat pump performance and the performance data from the manufacturer.

A calibrated water to water heat pump model with a scroll compressor is presented in this paper, based on the work of Jin (2002). The model relies on a simplified vapor compression cycle with 5 refrigerant states, where 
only 3 of the states need to have refrigerant thermodynamic properties evaluated. The model is implemented into the Modelica Buildings library (Wetter et al., 2014). An external implementation of the heat pump model into Python is used to obtain the calibrated model parameters based on tabulated manufacturer data. The computational efficiency of the Modelica model is tested in the simulation of a hydronic heating system.

\section{Heat Pump Model}

A heat pump model has been built from components from - and components added to - the Buildings library (Wetter et al., 2014). The model presented in this paper is for a water to water heat pump with a scroll compressor using refrigerant $\mathrm{R} 410 \mathrm{~A}$ and is shown in Figure 1. The heat pump model incorporates two new component models, Buildings.Fluid. HeatExchangers.EvaporatorCondenser for the evaporator and condenser and Buildings.Fluid. HeatPumps. Compressors.ScrollCompressor for the scroll compressor, as well as a refrigerant package for the thermodynamic properties of R410A Buildings. Media.Refrigerants.R410A.

The heat pump model is based on the work of Jin (2002), and has been extended to allow for single- and variable-speed compressors and dynamic heat storage on the water side. The model relies on a simplified vapor compression cycle, which removes the need to explicitly model the expansion device. The model is meant to use parameters for the sub-components, obtained from calibration of the model to manufacturer data.

The vapor compression cycle and the refrigerant, evaporator, condenser and compressor models and their implementation in Modelica are presented in this section.

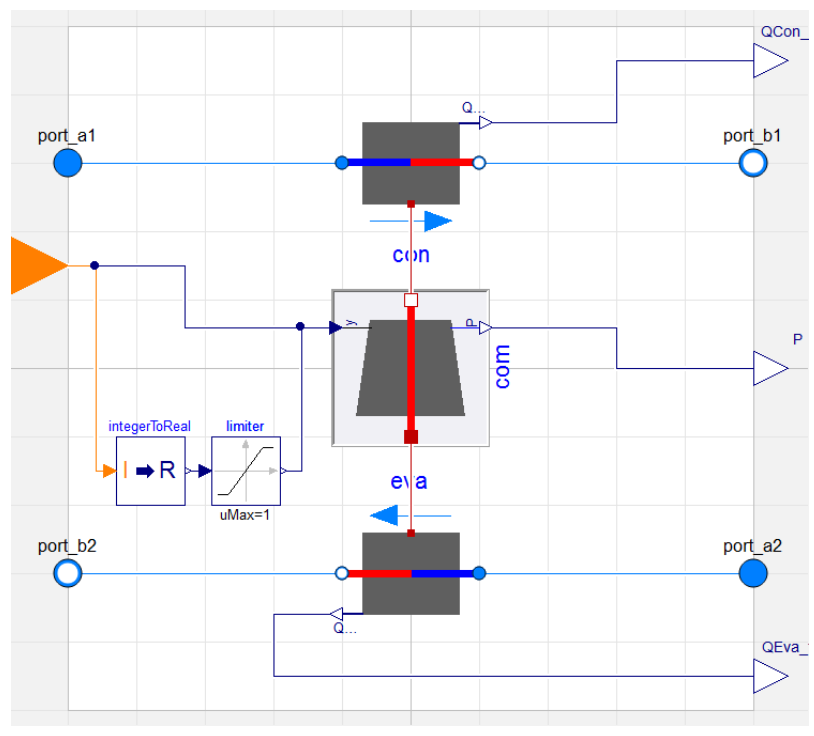

Figure 1. Model of a water to water heat pump with a scroll compressor.

\subsection{Simplified Vapor Compression Cycle}

A simplified vapor compression heat pump cycle, as proposed by Jin (2002), is presented in Figure 2. The simplified cycle serves two purposes: (1) to reduce the number of parameters in the heat pump model and thereby facilitate the calibration process, and (2) to reduce the number of evaluations of thermodynamic properties of the refrigerant and thereby reduce computing time.

The simplified vapor compression cycle relies on the following assumptions:

1. The refrigerant leaves the condenser in the saturated liquid state, i.e. there is no subcooling of the refrigerant.

2. The refrigerant leaves the evaporator in the superheated vapor state, with a constant degree of superheating $\Delta T_{\text {sup }}$. The enthalpy increase from superheating has been magnified in Figure 2 and is usually small compared to the latent heat of evaporation.

3. The theoretical compressor work is the result of isentropic compression at the built-in volume ratio followed by isochoric compression or expansion to the condensing pressure.

4. Sensible heat transfer to the refrigerant is neglected in the evaporator.

5. The expansion process is isenthalpic.

From this set of assumptions, only a limited number of refrigerant thermodynamic properties need to be evaluated to solve the complete vapor compression cycle: the temperatures, pressures and specific enthalpies of the saturated vapor and saturated liquid refrigerant (i.e. points $\mathrm{A}$ and $\mathrm{B}$ ), and the specific volume and isentropic exponent of the superheated vapor refrigerant (i.e. point $\mathrm{C}$ ).

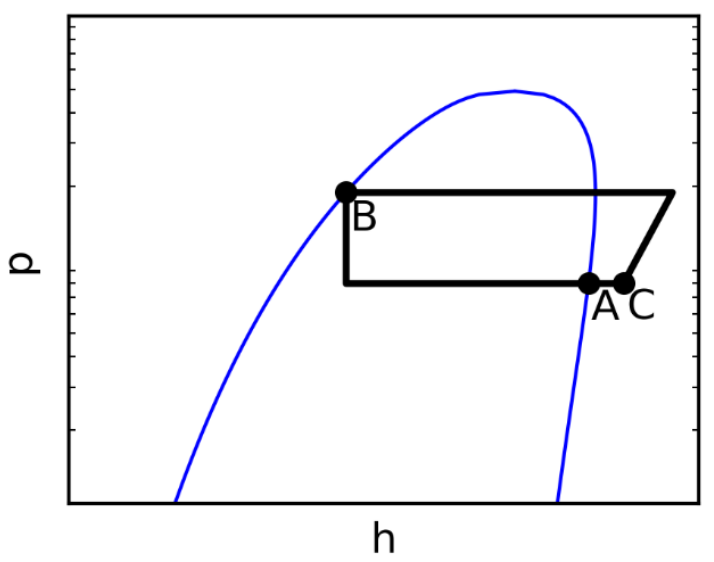

Figure 2. Simplified vapor compression cycle.

\subsection{Refrigerant Properties}

The necessary routines for the evaluation of the thermodynamic properties of refrigerant R410A were implemented in a media package. Except for the 
enthalpy of saturated refrigerant vapor, coefficients for the equations presented in this section were obtained from commercial supplier data (du Pont, 2004). Coefficients for the enthalpy of saturated refrigerant vapor were produced from tabulated properties in the supplier data.

The implemented refrigerant routines and their associated inputs are presented in Table 1. Specific enthalpies and pressures of the saturated liquid and saturated vapor refrigerant are calculated from degree 5 polynomial correlations. Thermodynamic properties of the superheated refrigerant vapor are calculated using the 11-term Martin-Hou equation of state (Martin and Hou, 1955). Note that temperatures in all equations related to thermodynamic properties are in Kelvin.

Table 1. Refrigerant routines.

\begin{tabular}{|l|c|}
\hline Output & Input $(s)$ \\
\hline Specific enthalpy (Saturated liquid), $h$ & $T$ \\
\hline Pressure (Saturated liquid), $p$ & $T$ \\
\hline Specific enthalpy (Saturated vapor), $h$ & $T$ \\
\hline Pressure (Saturated vapor), $p$ & $T$ \\
\hline Isentropic exponent (Vapor), $\gamma$ & $v, T$ \\
\hline $\begin{array}{l}\text { Specific isobaric heat capacity (Vapor), } \\
c_{p}\end{array}$ & $v, T$ \\
\hline $\begin{array}{l}\text { Specific isochoric heat capacity (Vapor), } \\
c_{v}\end{array}$ & $v, T$ \\
\hline Specific volume (Vapor), $v$ & $p, T$ \\
\hline
\end{tabular}

The specific enthalpy and pressure of saturated liquid and saturated vapor refrigerant are calculated from degree 5 polynomial correlations of the following form:

$$
\begin{gathered}
h=\sum_{i=1}^{6} a_{i} X_{h}^{i-1} \\
\ln \left(p / p_{\text {cri }}\right)=\sum_{i=1}^{6} a_{i} X_{p}^{i-1}
\end{gathered}
$$

where $p_{\text {cri }}$ is the critical pressure $(=4926.1 \mathrm{kPa}$ for $\mathrm{R} 410 \mathrm{~A}), X_{h}=\left(1-T / T_{c r i}\right)^{1 / 3}-X_{0}, T_{c r i}$ is the critical temperature $\left(=72.13^{\circ} \mathrm{C}\right.$ for $\left.\mathrm{R} 410 \mathrm{~A}\right), \quad X_{p}=(1-$ $\left.T / T_{c r i}\right)-X_{0}$, and $a_{i}$ and $X_{0}$ are correlation coefficients that differ for Eqs. 1 and 2 and for saturated liquid and saturated vapor.

The specific volume of the superheated vapor refrigerant is evaluated from the Martin-Hou equation of state:

$$
p=\frac{R T}{v-b_{0}}+\sum_{i=1}^{4} \frac{a_{i}+b_{i} T+c_{i} \exp \left(-k \frac{T}{T_{c r i}}\right)}{\left(v-b_{0}\right)^{i+1}}
$$

where $R$ is the gas constant $\left(=0.11455 \mathrm{~kJ} /\left(\mathrm{kg} \cdot{ }^{\circ} \mathrm{C}\right)\right.$ for $\mathrm{R} 410 \mathrm{~A})$, and $a_{i}, b_{i}, c_{i}$ and $k$ are coefficients to the equation of state.
During the development of the heat pump model, it was found that the numerical solver needs to solve Eq. 3 for $v$. In many cases, the numerical solver could not converge since it could not choose a proper guess value for $v$. A refrigerant routine was then implemented to evaluate the specific volume based on pressure and temperature by successive evaluation of $p$ and $\frac{\partial p}{\partial v}$, starting from a guess value $v_{\text {guess }}=R T / p+b_{0}$. This leads to an efficient implementation of the inverse of Eq. 3 , as the guess value $v_{\text {guess }}$ is relatively close to the final value.

The isentropic exponent is calculated from the derivatives and integrals of the equation of state (de Monte, 2002):

$$
\begin{gathered}
\gamma=c_{p} / c_{v} \\
c_{p}=c_{v}-T\left(\left.\frac{\partial p}{\partial T}\right|_{v, T}\right)^{2} /\left.\frac{\partial p}{\partial v}\right|_{v, T} \\
c_{v}=c_{p, i d}-R-\left.T \int_{\infty}^{v} \frac{\partial^{2} p}{\partial T^{2}}\right|_{v^{\prime}, T} d v^{\prime}
\end{gathered}
$$

The derivatives and integrals in Eqs. 5 and 6 are calculated directly by implementations of the corresponding derivatives and integrals of the equation of state in Eq. 3. The specific isobaric heat capacity of ideal gas, $c_{p, i d}$, is evaluated from a degree 3 polynomial correlation based on temperature, in the form:

$$
c_{p, i d}=\sum_{i=1}^{4} a_{i} T^{i-1}
$$

where $a_{i}$ are correlation coefficients.

\subsection{Compressor}

The compressor model solves the complete vapor compression cycle presented in Section 2.1. The model interfaces with the evaporator and condenser models through HeatPorts. The temperature and heat transfer rates at the ports correspond to the refrigerant temperature and heat transfer rates in the evaporator and condenser.

The scroll compressor model proposed by Jin (2002) was implemented and extended to consider variablespeed compressors. As outlined in Section 2.1, the theoretical compressor work is the result of isentropic compression at the built-in volume ratio followed by isochoric compression or expansion to the condensing pressure. The volume ratio between discharge and suction of the scroll compressor is fixed and the compressor work must be adjusted if the pressure ratio does not match the pressure ratio obtained from isentropic compression at the fixed volume ratio. The theoretical compressor work is then: 


$$
\begin{aligned}
& \dot{W}_{t}=\frac{\gamma}{\gamma-1} p_{\text {eva }} y \dot{V}_{\text {nominal }}\left(\frac{\gamma-1}{\gamma} \frac{p_{\text {con }}}{p_{\text {eva }} V_{r}}\right. \\
& \left.+\frac{1}{\gamma} p_{r}^{\frac{\gamma-1}{\gamma}}-1\right)
\end{aligned}
$$

where $\dot{W}_{t}$ is the theoretical compressor work, $p_{\text {eva }}$ and $p_{c o n}$ are the evaporating and condensing pressure, $y$ is the normalized speed of the compressor, with $y=1$ the value at the nominal speed, $\dot{V}_{\text {nominal }}$ is the nominal refrigerant volume flow rate, $V_{r}$ is the "built-in" volume ratio between discharge and suction of the compressor and $p_{r}=V_{r}^{\gamma}$ is the "built-in" pressure ratio.

The theoretical compressor work is adjusted for the electro-mechanical efficiency of the compressor to obtain the power input into the compressor. A constant electro-mechanical efficiency is assumed:

$$
\dot{W}=\frac{\dot{W}_{t}}{\eta}+\dot{W}_{\text {loss }}
$$

where $\dot{W}$ is the power input into the compressor, $\eta$ is the electro-mechanical efficiency of the compressor and $\dot{W}_{\text {loss }}$ is the constant part of the compressor power losses.

Since sensible heat transfer is neglected in the evaporator and expansion is considered isenthalpic, the evaporator heat transfer rate is obtained from the enthalpy difference between the enthalpy of saturated vapor at the evaporating pressure (point A in Figure 2) and the enthalpy of saturated liquid at the condensing pressure (point B in Figure 2):

$$
\dot{Q}_{\text {eva }}=y\left(\frac{\dot{V}_{\text {nominal }}}{v_{\text {suc }}}-\dot{m}_{\text {leak }}\right)\left(h_{A}-h_{B}\right)
$$

where $\dot{Q}_{e v a}$ is the evaporator heat transfer rate, $v_{s u c}$ is the specific volume at the suction of the compressor (point $\mathrm{C}$ in Figure 2) and $\dot{m}_{\text {leak }}=C \frac{p_{c o n}}{p_{e v a}}$ is the leakage mass flow rate in the compressor, with $C$ being the leakage coefficient.

The condenser heat transfer rate is then evaluated from an energy balance:

$$
\dot{Q}_{\text {con }}=-\left(\dot{Q}_{\text {eva }}+\dot{W}\right)
$$

where $\dot{Q}_{c o n}$ is the condenser heat transfer rate.

The specific enthalpies $h_{A}$ and $h_{B}$ are evaluated from the implemented refrigerant routines presented in Table 1 for the saturated liquid at $T=T_{\text {con }}$ the condensing temperature and the saturated vapor at $T=$ $T_{e v a}$ the evaporating temperature. The specific volume at suction is evaluated for $p=p_{e v a}$ and $T=T_{e v a}+$ $\Delta T_{\text {sup }}$, where $T$ is the temperature of the superheated vapor at the compressor suction. The evaporating and condensing pressure used in Eq. 8 are evaluated from the refrigerant routines for the pressure of saturated vapor evaluated at $T=T_{\text {eva }}$ and $T=T_{\text {con }}$. The isentropic exponent used in Eq. 8 is evaluated at $v=$ $v_{\text {suc }}$ and $T=T_{\text {eva }}+\Delta T_{\text {sup }}$. Superheating of the refrigerant is included in the compressor model and not in the evaporator model. Only the effects of superheating on the suction specific volume and isentropic exponent are considered. The superheating enthalpy increase is neglected.

\subsection{Evaporator and Condenser}

The evaporator and condenser model is shown in Figure 3. It extends from the already implemented TwoPortHeatMassExchanger of the Buildings library. It interfaces with the compressor model through a HeatPort. The refrigerant in both the evaporator and condenser is assumed to exchange heat with the fluid stream at a constant temperature. The effective heat transfer coefficient $U A_{\text {eff }}$ between the refrigerant and the fluid is calculated by the $\varepsilon-N T U$ method:

$$
\begin{gathered}
N T U=U A / \dot{m}_{f} c_{p, f} \\
\varepsilon=1-\exp (-N T U)
\end{gathered}
$$

where $N T U$ is the number of transfer units, $\varepsilon$ is the heat exchanger effectiveness, $U A$ is the heat transfer coefficient of the evaporator or condenser, $\dot{m}_{f}$ is the fluid mass flow rate and $c_{p, f}$ is the fluid specific isobaric heat capacity.

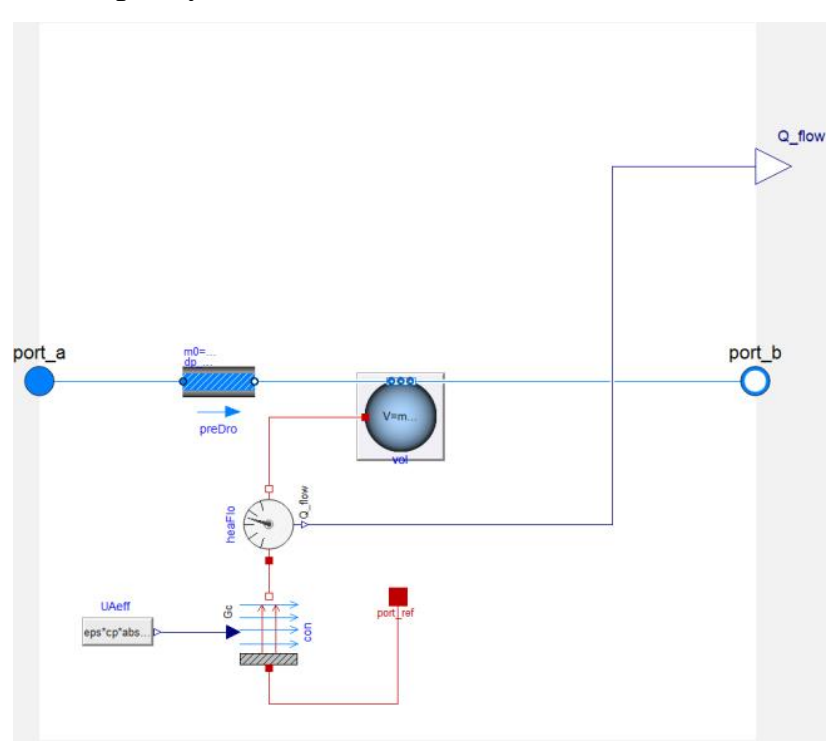

Figure 3. Model used for both the evaporator and condenser of the heat pump.

The effective heat transfer coefficient is then evaluated based on the outlet fluid temperature, since the HeatPort of the MixingVolume returns the outlet fluid temperature. The heat transfer rate is given by:

$$
\begin{array}{r}
\left\{\dot{Q}_{\text {eva }}, \dot{Q}_{\text {con }}\right\}=U A_{\text {eff }}\left(\left\{T_{\text {eva }}, T_{\text {con }}\right\}\right. \\
\left.-T_{f, \text { out },\{\text { eva }, \text { con }\}}\right) \\
U A_{\text {eff }}=\varepsilon c_{p, f} \dot{m}_{f} /(1-\varepsilon)
\end{array}
$$

where $T_{f, \text { out },\{\text { eva,con }\}}$ is the outlet fluid temperature in the evaporator or condenser. 


\section{Model Calibration}

The parameters required by the heat pump subcomponent models are typically not provided by the heat pump manufacturers. These parameters therefore need to be determined by calibrating the model to the manufacturer data. There are 8 parameters that need to be evaluated: the nominal refrigerant flow rate $\dot{V}_{\text {nominal }}$, the volume ratio $V_{r}$, the leakage coefficient $C$, the degree of superheating $\Delta T_{\text {sup }}$, the electro-mechanical efficiency $\eta$, the constant part of the power losses $\dot{W}_{\text {loss }}$ and the heat transfer coefficients $U A_{\text {eva }}$ and $U A_{\text {con }}$ of the evaporator and condenser.

Manufacturers usually provide technical data in the form of tabulated values of heat pump capacities and power input at different operating conditions in terms of inlet water temperatures and mass flow rates into the evaporator and condenser. Jin (2002) proposed the use of optimization methods to identify the set of parameters that minimize the sum of normalized square errors of the heat pump capacities and power inputs. The cost function to minimize is:

$$
\begin{aligned}
& \text { Cost }=\sum_{i}\left[\left(\frac{\dot{Q}_{\text {con }}^{(i)}-\dot{Q}_{\text {con,data }}^{(i)}}{\dot{Q}_{\text {con,data }}^{(i)}}\right)^{2}\right. \\
& \left.+\left(\frac{\dot{W}^{(i)}-\dot{W}_{\text {data }}^{(i)}}{\dot{W}_{\text {data }}^{(i)}}\right)^{2}\right]
\end{aligned}
$$

An optimization routine was set-up in Python using the SciPy (Jones et al., 2001) package. Analogous models for the refrigerant properties, the compressor, the evaporator and the condenser were implemented in Python. The set of parameters that minimizes the cost function are evaluated from the Python model using a sequential least square programming method. Once the parameters are evaluated, the Python implementation of the heat pump model is verified against the Modelica model.

The time required to calibrate the model increases with the number of manufacturer data points that are used. Jin (2002) showed that using the combinations of maximum and minimum entering water temperature and mass flow rates on the evaporator and condenser sides, for a total of 16 data points, decreases the calibration time significantly with minimal effect on the accuracy of the calibrated model. The Python optimization routine thus only uses a subset of 16 data points from the manufacturer data, and compares the model with the complete manufacturer data set once the calibration is complete.

Not all combinations of parameters yield a valid heat pump model. For example, certain sets of parameters may result in refrigerant temperatures in the condenser to be greater than the critical temperature. In these cases, it is not possible for the model to evaluate the capacity and power input of the heat pump, since property routines for saturated refrigerant (Eqs. 1 and 2) are only valid for temperatures below the critical temperature.

It is then important to choose proper guess values for the parameters when calibrating the model. Guess values of the electro-mechanical efficiency and the degree of superheating are simply chosen to be $\eta=0.95$ and $\Delta T_{\text {sup }}=4^{\circ} \mathrm{C}$. The rest of the parameters are evaluated from the nominal values of the heat pump capacity $\dot{Q}_{\text {con,nominal }}$, power input $\dot{W}_{\text {nominal }}$ and corresponding entering water temperatures $T_{f, \text { in,eva,nominal }}$ and $T_{f, \text { in,con,nominal }}$, assuming a $5^{\circ} \mathrm{C}$ temperature difference between the inlet fluid temperatures and the refrigerant temperatures and a $1 \%$ leakage mass flow rate. The guess values of the parameters are evaluated following this sequence:

1. Evaluate the refrigerant temperatures:

$$
\begin{aligned}
& T_{\text {eva }}=T_{f, \text { in,eva,nominal }}-5^{\circ} \mathrm{C} \\
& T_{\text {con }}=T_{f, \text { in,con,nominal }}+5^{\circ} \mathrm{C}
\end{aligned}
$$

2. Evaluate the evaporator heat transfer rate at nominal conditions:

$$
\dot{Q}_{\text {eva,nominal }}=\dot{W}_{\text {nominal }}-\dot{Q}_{\text {con,nominal }}
$$

3. Evaluate the evaporating pressure $p_{\text {eva }}$ and condensing pressure $p_{\text {con }}$ at the corresponding refrigerant temperature from the refrigerant routines.

4. With the suction temperature $T=T_{\text {eva }}+\Delta T_{\text {sup }}$ and evaporating pressure $p_{\text {eva }}$, evaluate the specific volume and isentropic exponent from the refrigerant routines.

5. Evaluate the volume ratio:

$$
V_{r}=\left(p_{\text {con }} / p_{\text {eva }}\right)^{1 / \gamma}
$$

6. Evaluate the nominal refrigerant volume flow rate:

$$
\begin{gathered}
\dot{V}_{\text {nominal }}=\left(\dot{m}_{\text {ref }}+\dot{m}_{\text {leak }}\right) v_{\text {suc }} \\
\dot{m}_{\text {ref }}=-\frac{\dot{Q}_{\text {eva,nominal }}}{\left(h_{A}-h_{B}\right)} \\
\dot{m}_{\text {leak }}=0.01 \dot{m}_{\text {ref }}
\end{gathered}
$$

7. Evaluate the leakage coefficient:

$$
C=\dot{m}_{\text {leak }} /\left(p_{\text {con }} / p_{\text {eva }}\right)
$$

8. With the theoretical power evaluated from Eq. 8 and the previously evaluated parameters, evaluate the constant part of the power losses:

$$
\dot{W}_{\text {loss }}=\max \left(0, \eta \dot{W}_{\text {nominal }}-\dot{W}_{t}\right)
$$

9. Evaluate the condenser and evaporator heat transfer coefficients:

$$
\left\{U A_{\text {con }}, U A_{\text {eva }}\right\}=\dot{Q}_{\text {con,nominal }} / 5^{\circ} \mathrm{C}
$$

This sequence has been implemented in Python and is used to choose starting values for the parameters. It was found to produce valid parameters in all cases considered. 


\section{Examples}

\subsection{Calibration from Model Produced Data}

The calibration method for the heat pump model is first verified using data produced by the model. Heat pump capacities and power input were calculated using the Python model for water mass flow rates of $0.6,0.9$ and $1.2 \mathrm{~kg} / \mathrm{s}$ at both the evaporator and condenser, inlet water temperatures of $0,5,10,15,20$ and $25^{\circ} \mathrm{C}$ at the evaporator and inlet water temperatures of $15,25,35$ and $45^{\circ} \mathrm{C}$ at the condenser, for a total of 216 data points. The calibration is done using only the 16 points corresponding to the combinations of minimum and maximum values of the inlet water temperatures and flow rates. The set of parameters used to evaluate the heat pump capacities and power input, the guess values for each parameter and the set of parameters resulting from the calibration are shown in Table 2. A comparison of the heat pump capacities and input power at all 216 points for the model values and calibrated values is shown in Figure 4.

Table 2. Heat pump parameters for calibration using model produced data.

\begin{tabular}{|l|l|l|l|}
\hline Parameter & $\begin{array}{l}\text { Original } \\
\text { value }\end{array}$ & $\begin{array}{l}\text { Guess } \\
\text { value }\end{array}$ & $\begin{array}{l}\text { Calibrate } \\
\text { d value }\end{array}$ \\
\hline$V_{r}(-)$ & 2.365 & 1.668 & 2.362 \\
\hline $\begin{array}{l}\dot{V}_{\text {nominal }} \\
\left(\mathrm{m}^{3} / \mathrm{s}\right)\end{array}$ & 0.00288 & 0.00193 & 0.00287 \\
\hline$C(\mathrm{~kg} / \mathrm{s})$ & 0.0041 & 0.00049 & 0.0041 \\
\hline$\Delta T_{\text {sup }}\left({ }^{\circ} \mathrm{C}\right)$ & 6.84 & 4.00 & 6.49 \\
\hline$\eta(-)$ & 0.924 & 0.950 & 0.922 \\
\hline$\dot{W}_{\text {loss }}(\mathrm{W})$ & 396.1 & 2206 & 398.7 \\
\hline$U A_{\text {con }}\left(\mathrm{W} /{ }^{\circ} \mathrm{C}\right)$ & 7007.7 & 5044.9 & 7014.5 \\
\hline$U A_{\text {eva }}\left(\mathrm{W} /{ }^{\circ} \mathrm{C}\right)$ & 29991 & 5044.9 & 49136 \\
\hline
\end{tabular}

The calibration process yielded parameters within $0.7 \%$ of the model value, except for the degree of superheating $(5.1 \%)$ and the heat transfer coefficient of the evaporator (64\%). The model appears not be very sensitive to the heat transfer coefficient of the evaporator. For instance, the sum of normalized square errors (Eq. 16) is $8.94 \times 10^{-6}$ using the calibrated values and $1.344 \times 10^{-5}$ when replacing only the heat transfer rate of the evaporator with the model value. The computing time for the calibration of the model was $80.5 \mathrm{sec}$.

\subsection{Calibration from Manufacturer Data}

The calibration method is also verified against commercial heat pump data. Technical data for a commercial water to water heat pump with $19.3 \mathrm{~kW}$ nominal capacity and 4.5 nominal coefficient of performance was used to calibrate the heat pump model. The technical data includes values of the capacity and power input for mass flow rates of $0.47,0.71$ and $0.94 \mathrm{~kg} / \mathrm{s}$ at both the evaporator and condenser, inlet water temperatures of $-1.2,4.5,10.1,15.6,21.2$ and $26.7^{\circ} \mathrm{C}$ at the evaporator and inlet water temperatures of $15.6,26.7,37.8$ and $48.9^{\circ} \mathrm{C}$ at the condenser, for a total of 216 data points. Once again, the calibration is done using only the 16 points corresponding to the combinations of minimum and maximum values of the inlet water temperatures and flow rates. The guess values for each parameter and the set of parameters resulting from the calibration are shown in Table 3. A comparison of the heat pump capacities and input power at all 216 points for the model values and calibrated values is shown on Figure 5.
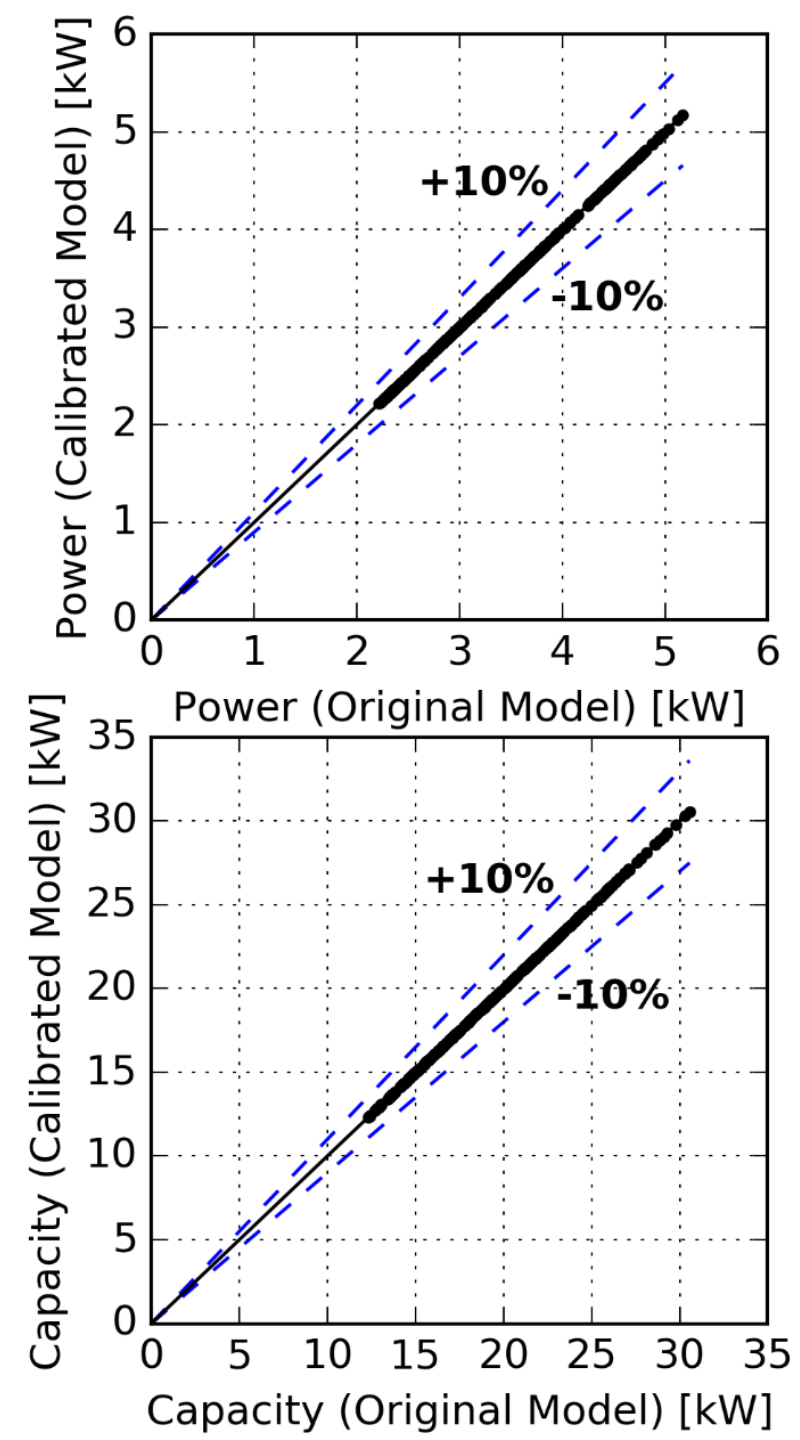

Figure 4. Comparison of model produced and calibrated model heat pump capacities and power input.

Overall, the calibrated model is in good agreement with the manufacturer data. The sum of the normalized square errors is 0.00507 and the maximum differences between calculated heat pump capacities and power input from the model and the manufacturer data are 
$2.7 \%$ and $4.7 \%$, respectively. Similar results have been obtained for different technical data from different manufacturers. The computing time for the calibration of the model was $72.3 \mathrm{sec}$. A database of sets of parameters, provided via Records, for various heat pumps from different manufacturers will be included with the heat pump model.
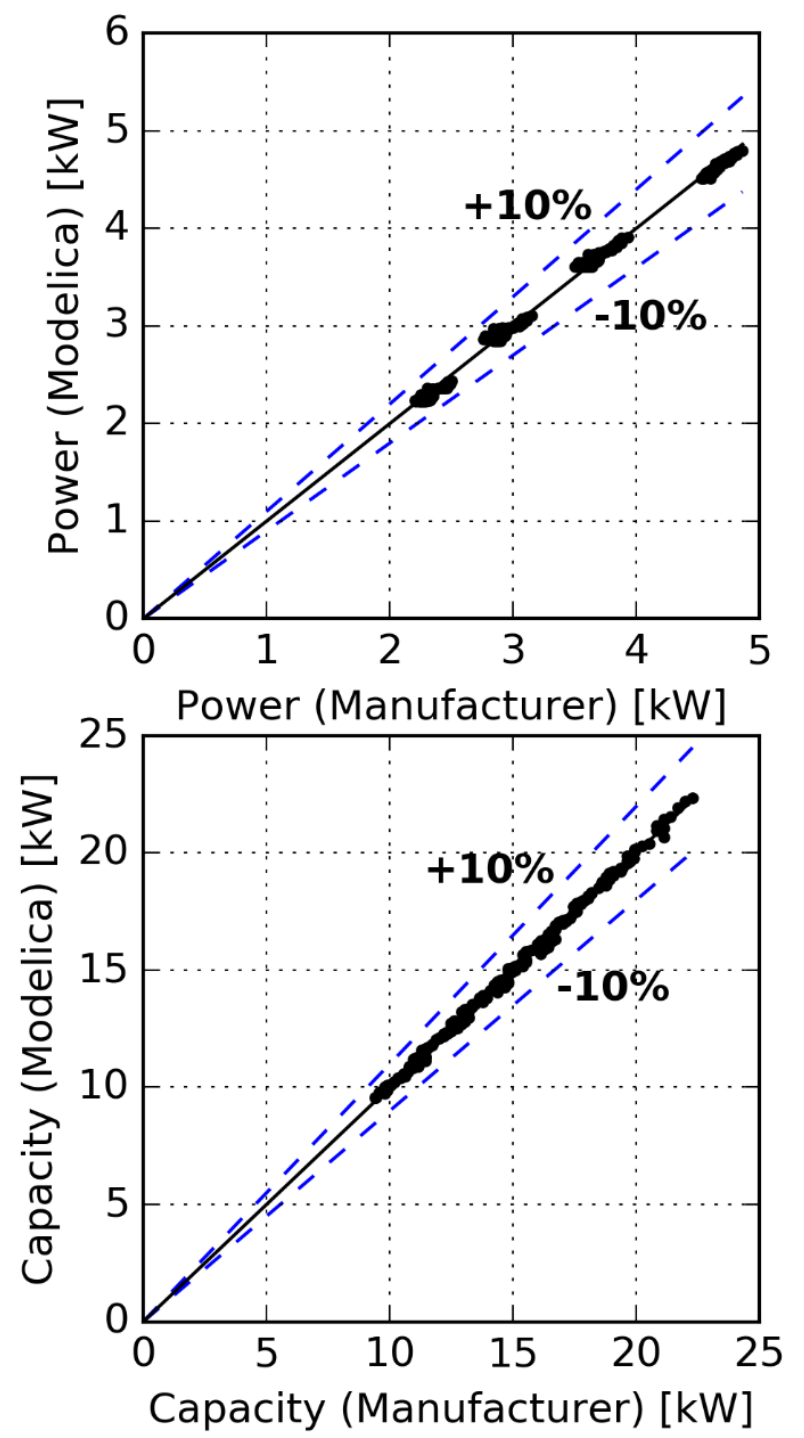

Figure 5. Comparison of manufacturer and calibrated model heat pump capacities and power input.

\subsection{Hydronic Heating System}

The heat pump model is integrated into a simulation model of a hydronic heating system. The system model is equivalent to the Buildings. Examples. HydronicHeating. TwoRoomsWithStorage system model from the Buildings library, with the boiler replaced by a water to water heat pump with a constant source temperature of $8^{\circ} \mathrm{C}$.

The hydronic heating system consists of two rooms equipped with radiators. Hot water is produced by the heat pump, stored into a storage tank and fed to the radiators when required. The radiators are turned on when the room temperature falls below the temperature set points of $21^{\circ} \mathrm{C}$ during the day and $16^{\circ} \mathrm{C}$ at night. The heat pump is turned on if the supply water temperature from the radiators falls below the current set point and turned off when the temperature at the bottom of the storage tank rises above $55^{\circ} \mathrm{C}$. Cooling is provided by outside air if the room temperatures rise above $22^{\circ} \mathrm{C}$.

Table 3. Heat pump parameters for calibration using manufacturer data.

\begin{tabular}{|l|l|l|}
\hline Parameter & Guess value & $\begin{array}{l}\text { Calibrated } \\
\text { value }\end{array}$ \\
\hline$V_{r}(-)$ & 1.436 & 1.975 \\
\hline $\begin{array}{l}\dot{V}_{\text {nominal }} \\
\left(\mathrm{m}^{3} / \mathrm{s}\right)\end{array}$ & 0.001484 & 0.001984 \\
\hline$C(\mathrm{~kg} / \mathrm{s})$ & 0.0004947 & 0.002566 \\
\hline$\Delta T_{\text {sup }}\left({ }^{\circ} \mathrm{C}\right)$ & 4.0 & 5.703 \\
\hline$\eta(-)$ & 0.95 & 0.8192 \\
\hline$\dot{W}_{\text {loss }}(\mathrm{W})$ & 2134 & 856.9 \\
\hline$U A_{\text {con }}\left(\mathrm{W} /{ }^{\circ} \mathrm{C}\right)$ & 6633.2 & 2840.4 \\
\hline$U A_{\text {eva }}\left(\mathrm{W} /{ }^{\circ} \mathrm{C}\right)$ & 6633.2 & 21523 \\
\hline
\end{tabular}

The nominal heating power of the boiler in the original system is $2.2 \mathrm{~kW}$. Therefore, the parameters to the heat pump model were the same as those presented in Table 3, with parameters $\dot{V}_{\text {nominal }}, C, \dot{W}_{\text {loss }}, U A_{\text {con }}$ and $U A_{\text {eva }}$ scaled by a factor 0.125 to obtain approximately the same heating capacity.

The simulation time for the simulation model using the heat pump is compared to the simulation time for the model using the boiler. Both simulations are done using the Radau solver, a tolerance of $1 \times 10^{-6}$ and a simulation stop time of 1 week. The simulation time using the heat pump model was 48 seconds while the simulation time using the boiler was 17 seconds.

\section{Conclusions}

A model for a water to water heat pump with a scroll compressor is presented. To keep the computational time small and to reduce the number of evaluations of refrigerant thermodynamic properties, the model is based on a simplified vapor compression cycle with only five refrigerant states. Components for the compressor, the evaporator and condenser, as well as routines for the evaluation of thermodynamic properties of refrigerant R410A were implemented in Modelica. Parameters to the model are evaluated from manufacturer data by solving the optimization problem that minimizes the differences between the model predicted heat pump capacities and power input and those found in the manufacturer technical data.

The heat pump model was also implemented in Python to facilitate the calibration process. While it 
would be possible to call the Modelica model during the optimization, a Python implementation was judged more convenient in terms of ease of use. However, it duplicates the implementation of the heat pump model, which would make it difficult to apply the same methodology to more complex systems. Support for the preprocessing of parameters using Modelica models within the Modelica framework would facilitate the use of calibrated Modelica models.

The calibrated model presented in this paper has been shown to generate heat pump capacities and power input very close to the manufacturer data, and to be able to be integrated into simulation models with minimal impact on the simulation time. Future work will be devoted to the extension of the methodology to more complex cycles, such as multi-stage cycles, and to the modeling of chillers.

\section{Acknowledgements}

This research was supported by the Assistant Secretary for Energy Efficiency and Renewable Energy, Office of Building Technologies of the U.S. Department of Energy, under Contract No. DE-AC02-05CH11231.

\section{References}

Carbonell, S. D., Cadafalch, R. J., Pärlisch, P., and Consul, S. R. (2012). Numerical analysis of heat pumps models: comparative study between equation-fit and refrigerant cycle based models. in Proc. Int. Conf. on Solar Heating, Cooling and Buildings, EuroSun 2012 (Rijeka, HR).

De Monte, F. (2002). Calculation of thermodynamic properties of $\mathrm{R} 407 \mathrm{C}$ and $\mathrm{R} 410 \mathrm{~A}$ by the Martin-Hou equation of state - part I: theoretical development. International Journal of Refrigeration, 25(3): 306-313.

Domanski, P. A., and McLinden, M. O. (1992). A simplified cycle simulation model for the performance rating of refrigerants and refrigerant mixtures. International Journal of Refrigeration, 15(2): 81-88.

E. I. du Pont de Nemours and Company (2004). Thermodynamic properties of du Pont Suva 410A refrigerant.

https://www.chemours.com/Refrigerants/en_US/assets/do wnloads/h64423_Suva410A_thermo_prop_si.pdf.

Jin, H. (2002). Parameter estimation based models of water source heat pumps. Ph.D. Thesis. Oklahoma State University, Stillwater, OK, USA.

Jones, E., Oliphant, T., and Peterson, P. (2001). Open source scientific tools for Python. URL http://www. scipy. org, 73, 86.

Lee, T. S., and Lu, W. C. (2010). An evaluation of empirically-based models for predicting energy performance of vapor-compression water chillers. Applied Energy, 87(11): 3486-3493.

Lemort, V., and Bertagnolio, S. (2010). A Generalized Simulation Model of Chillers and Heat Pumps to be Calibrated on Published Manufacturer's Data. In Proceedings of the International Symposium on Refrigeration Technology 2010, Zhuhai, China.
Lund, H., Werner, S., Wiltshire, R., Svendsen, S., Thorsen, J. E., Hvelplund, F., and Mathiesen, B. V. (2014). 4th Generation District Heating (4GDH): Integrating smart thermal grids into future sustainable energy systems. Energy, 68: 1-11.

Martin, J. J., and Hou, Y. C. (1955). Development of an equation of state for gases. AIChE Journal, 1(2): 142-151.

Scarpa, M., Emmi, G., and De Carli, M. (2012). Validation of a numerical model aimed at the estimation of performance of vapor compression based heat pumps. Energy and Buildings, 47: 411-420.

Swider, D. J. (2003). A comparison of empirically based steady-state models for vapor-compression liquid chillers. Applied Thermal Engineering, 23(5): 539-556.

Wetter, M., Zuo, W., Nouidui, T. S., and Pang, X. (2014). Modelica Buildings library. Journal of Building Performance Simulation, 7(4): 253-270. 